International Journal of Geography and Geology

2013 Vol. 2, No. 6, pp. 70-79

$\operatorname{ISSN}(e): 2305-7041$

$\operatorname{ISSN}(p):$ 2306-9872

DOI: 10.18488/journal.10/2013.2.6/10.6.70.79

(C) 2013 Conscientia Beam. All Rights Reserved.

(2) CrossMark

\title{
INVESTIGATION INTO THE REALIZATION OF NATURALISM IN HASHTGERD NEW TOWN BASED ON THE IRANIAN ISLAMIC MODEL
}

\author{
Abolfazl Meshkini ${ }^{1}$--- Akram Ghasemi ${ }^{2}$--- Mahdi Hamzehnejad ${ }^{3}$--- Azita Belali \\ Oskui $^{4}$ \\ ${ }^{1,2}$ Faculty of Humanities, Tarbiat Modares University, Tehran \\ ${ }^{3,4}$ Faculty of Architecture, Iran University of Science and Technology, Tehran
}

\begin{abstract}
Naturalism has been regarded as one of the most significant indices of the appraisal of the identity of Iranian Islamic cities. This index, by the emergence of the new era, in spite of the lucidity in the urban structures, is not deemed as an identity determiner owing to its combination with other elements, and consequently taking new roles and functions. This study focused on naturalism manifested in the presence of natural elements such as water, fountains, ponds, pools, water running in water paths on either side of roadways and streets, green spaces, the sun shining, and the wind flowing. In order to evaluate the index of naturalism in the design of Hashtgerd New Town, 379 inhabitants of this city participated in the present study. This is an applied research and a descriptive-analytical approach was utilized. For data collection, methods of library and field research were adopted. For data analysis, Frequency, Mean, and Standard Deviation were estimated and a One-sample T-test was conducted via SPSS software. The results revealed that the index of naturalism in line with the unique criteria of Iranian Islamic urban construction has been overlooked by the urban designers and constructors of Hashtgerd New Town.
\end{abstract}

Keywords: Urban planning and design Iranian Islamic, Natural elements, Naturalism, Hashtgerd New Town.

Received: 14 June 2013/ Revised: 24 July 2013/ Accepted: 26 July 2013/ Published: 30 July 2013

\section{INTRODUCTION}

\subsection{Introduce the Problem}

The concept of Nature in all religions and cultures has received numerous attention and deference; based on the culture inherited from Ancient Iran, Nature is comprised of four main elements (Water, Soil, Wind, and Light). In Islamic culture, these elements and other natural 
phenomena show the sure sign of the existence of God and are the constant reminiscences and reminders of this fact; critical thinking in, contemplation of, and reflection on them and on their relationship with each other would pave the way for human beings to know the universe better, which eventually leads them to know its creator and his Monotheistic feature. These points urge an intimate and perpetual relationship between human beings and Nature so as for them to be able to meditate on these divine revelations, to fully utilize them, and to exploit the principles and rules reigned over them for the purpose of providing an appropriate environment to live in; in other words, the understanding of whatever the holy Qur'an proclaims regarding the natural elements draws our attention towards the necessity of establishing the attached and incessant relationship between human beings and Nature in different moments of life and in various places (Taghi Zadeh, 2001). The study of historic cities of the Muslims indicates that even though the cities were located in the hot and arid areas, their formation and structure were meticulously done in such a way that they could be in harmony with Nature and they tried their best to strike the balance between artificial environment, Nature, human needs; in effect, Muslims' endeavor to specify natural elements' characteristics and to exploit natural rules has been aimed at constructing urban environments which are inhabitable, balanced, and well-suited for human beings to live in (Shakouei, 1986). Nowadays, it is substantiated that human's ceaseless bonding with Nature in urban environments, and the attempt at conserving Nature and natural sources play a crucial role in human survival. Unfortunately, the center of attention is devoted to the material and quantitative dimensions of life, and due to this fact other significant, but unheeded, dimensions that can be, and should be, taken notice of are somehow disregarded. It can be declared that the most unnoticed dimensions are the moral and spiritual importance of human relationship with Nature in his surrounding environment and his daily life. In other words, by the emergence of industrial revolution and the rapid expansion of industry in recent decades, the main focus of attention has been on taking the maximum economic advantage of Nature and natural sources without being much concerned about the irreparable damages that have threaten Nature, urban environments, and ultimately human beings. This has brought about the imbalance of urban functionalities and the destruction of natural environments in favor of artificial environments. This artificial environment, during whose formation process the development and expansion of the rare natural pristine environment are threatened and ruined, is void of any particular identity or of any kinds of architectural and urban constructional components in a way that the artificial environment can adjust and merge neither with the natural surroundings nor with Islamic Iranian urban construction criteria. Considering Hashtgerd New Town, as one of the most outstanding new cities, is built on a natural pristine land, the construction process is required to be in such a way that the generated artificial structure is in coordination with the existing natural identity, is in the direction of its components' improvement, and has an optimal and active interaction with the existing natural characteristics. This study is an attempt to account for the role and influence of natural elements and natural rules on human beings and their environments based on the Islamic culture and doctrine, and to argue for the requirement of establishing the continual relationship with nature in urban environments as a means of 
quenching human's thirst for spiritual life in accordance with the Islamic values' framework. Then the realization of the index of naturalism, as one of the most important indices of Iranian Islamic urban construction, in the design of Hashtgerd New Town has been explored; and based on the results, the extent to which this index has been taken into account by the urban designers and planners of Hashtgerd New Town was measured.

\section{METHOD}

The study is an applied research and is based on the descriptive-analytical method. Data collection was done using methods of library and field research. In the library method, various sources, such as books, articles, and maps, and in the field method, observation, interview, and questionnaire were utilized. The Likert Scale was picked out for designing the questionnaire. The number of the participants, all of whom live in Hashtgerd New Town was 379. This sample size was determined based on Cochran formula. In order to estimate the reliability, 35 participants accomplished a pretest in a pilot study, Cronbakh's alpha was run, and the final modifications of the statements were made. The result of Cronbakh's alpha was 0.7 , which proves the internal consistency. For the data analysis, Frequency, Mean, Standard Deviation and the results of the One-sample T-test, via SPSS, were reported and analyzed.

\section{CONCEPTS, VIEWS, AND THEORETICAL BASICS}

\subsection{Nature (concepts and views prevailing in Iran and in the World)}

In Oxford Dictionary, the word "Nature" is defined as the whole universe and all the creatures barring those that are made by human beings. The word "Nature" is derived from the Latin word "Natura" whose etymon is "Nat". "Nat" literally means "giving birth to and being born" which corroborates the ancient concept of Nature as a generator and of our being its children (Nasr, 2001). Primary Nature is described as the nature which remains intact and virgin, has not fallen into the hands of human beings yet, and consequently has not turned into a Secondary Nature; Secondary Nature is brought into existence by human beings. Gardens are regarded as Third Nature, since gardens are deemed to be the lucid representation of Primary and Secondary Natures or an artistic interpretation of a particular place and exclusively belong to particular people (Esprin, 2006). In the science pertaining to ecology, "natural environment" is considered as part of environment which is not constructed by human beings. On this basis, forests, orchards, seas, rivers, and the whole natural panorama are the components of the natural environment (Soltany, 1998).

Naturalism or the relationship with Nature is perceived variously in different sorts of attitudes and diverse civilizations; accordingly, Islamic ideology sets forth a unique perspective of naturalism. Noghrehkar categorized different sorts of attitudes towards human relationship with Nature prevailing in Iran and in the world into 5 groups as follows:

First attitude: This is a beyond Nature attitude in which human has an identity beyond Nature, so the start and finish of his life isn't bound to the Nature frontiers; therefore, he is obliged to stay away from the nature as much as possible and has nothing to do with it. Some 
examples of this outlook can be found in Plato's theory of platonic ideas world and the perspectives of ancient Sufis, of some Gnostics, and of Indian regulations.

Second attitude: This is the naturalism attitude in which human life comes into existence and ends up in Nature, after his demise his physical body would decompose and return to Nature. Nature and all its elements and phenomena ought to be revered and all humans are duty-bound to pay their respect to Nature, therefore, they can't and shouldn't contaminate it (Noghrehkar, 2009). The instances of this attitude can be seen in the convictions of Ancient Iran, some Indian American tribes (Nasr, 2000), Greeks, Particularism, Naturalism in Europe in 18th century and the early 19th century.

Third attitude: This is the human dominance over Nature. Rooted in this view, Nature is a means of and the source of the fulfillment of human's desires. Life is restricted to the material world, and human is required to do his best to take the most advantage of Nature and to establish supremacy over it. The most valuable knowledge is considered to be the knowledge about Nature and about finding the best way to achieve dominance over it. The most outstanding epitome of this attitude is the standpoint of western man, believing in modernism, regarding Nature (Kajy, 2000).

Fourth attitude: This view propounds the coalescence with Nature and its central theme proclaims the equal identity of Nature. Human is deemed to be part of Nature, in consequence human has a junior status to Nature, and as a result, he should not go after taking control of Nature. Nature is the final destination and fading away in Nature is the ultimate purpose of the life. Some instances of this outlook are the ancient religions of Chinese and Japanese people.

Fifth attitude: This outlook suggests coordination in Nature and professes the root of human life lays in Nature. Human possesses the equal identity with Nature at first, but human soars above Nature while facing the vicissitudes of his life journey, and in the end his identity turns into one beyond the identity of Nature. Based on this view, Nature is regarded as a cradle for human's growth, sublimation, and development from a material worldly phenomenon to a spiritual unworldly phenomenon. In essence, the religions of Ibrahamic, Christianity, Judaism, and Islam espouse such view of Nature; among them, just Islamic viewpoint and Muslims' stance take both theoretical and practical dimensions of this view into account (Noghrehkar, 2009).

\subsection{Natural Elements in the Urban Environment}

Natural elements can be classified in a wide range; but due to the lack of space, just those elements which can exert an influence on the urban environment are cited here (Taghi Zadeh, 2001) and (Taghi Zadeh, 2005):

Each natural element is the reminiscence, sign, and symbol of the divine and spiritual matters, concepts, and values; at the apex of this pyramid, the attention to the colossal power and knowledge of God is set. Light is a spectacular phenomenon and in Quran's didactic instructions is introduced as an emblem of and a sign of countless superlative and exquisite dimensions and concepts such as God, the Prophet Muhammad, the Holy Quran, guidance, faith, insight, and wisdom. The devoid of light denotes the shadow which holds deep eminent meanings in itself. 
Wind (weather), in addition to its role on the continuity of the life of many creatures living on the Earth Planet, also has significant roles on the adjustment of the regional climates (clouds' movements), pollution transference, reproduction of the plants, the good tidings of the God's blessing, the sign of God's existence, and also the retribution descended from God. Water, as the main constituent of life, implies great symbolic meanings, such as Heaven, life, sanitary, beauty, and thirst quenching. Different kinds of plants, in addition to their crucial role they play on the biological environs of human via producing oxygen and absorbing pollutions, refine the artificial environment and embody their own symbolic meanings. Plants represent Heaven and are good reminiscences of and convincing justification for the Resurrection. In some verses of the Holy Qur'an, God swears on some kinds of plants and some of them, whose names are explicitly mentioned in it, are specifically declared to be the blessing gifts of God. Other elements such as mountains, sky, and whatever exists in them (the moon, the sun, and stars) not only have great material worldly advantages, but also pave the way for the improvement of thought and the ability of reminiscence; moreover they play an important role on gleaning knowledge about time, places, and directions.

\section{THE DESCRIPTION OF THE AREA UNDER INVESTIGATION}

Hashtgerd New Town, being 4000 Hectare in area, is located on the southern slope of Alborz Mountains and on the edge of Central Desert of Iran; In terms of climate, it is situated in a mountainous region and has interior semi-arid and dry climate. Based on the general climate classification, the type of this area is Mediterranean. Concerning geographical measures, it is placed in the western part of Tehran Province with the altitude of 1310-1610 meters above the sea level and the longitude of 50 degrees $25^{\prime}$ and 50 degrees $55^{\prime}$ and the latitude of 35 degrees $45^{\prime}$ and 36 degrees 5 '. The average temperature, the average rainfall, and the average humidity in this region are respectively 13.8 Centigrade, $257 \mathrm{~mm}$, and $47 \%$ and the wind speed is less than 35 $\mathrm{km} / \mathrm{h}$. The prevailing wind often occurs in the summer, and blows predominantly from southeast towards northwest and vice versa. The type of the soil is of sand and grit, and it is homogenous at least to a depth of 15 meters (Rahimiyoun, 2011).

\subsection{The Role of Natural Components in Urban Identity}

Each city has its own unique natural status that distinguishes it from other cities. The natural characteristics of each city indicate some part of that city's identity; this can be considered as part of the whole natural urban identity framework. Some examples are mountain ranges, desert, and the wide natural mines around that city. The enquiry of natural components can be done in terms of six branches (Behzadfar and Barin, 2009):

1) General natural status (the geographical longitude and latitude of that city and the indices pertaining to them), 2) the geographical construction components (Topography, Hydrography, and the indices pertaining to them), 3) the natural construction components (rivers and valleys), 4) regional and natural structural components (variability of the soil type, plant covers, and the 
overflow of the river basins), 5) spot components (springs, hills, and things like that), 6) spotlinear components (the water path and things like that).

Table-1. The classification of the natural variables of Hashtgerd New Town

\begin{tabular}{|c|c|c|c|c|c|}
\hline $\begin{array}{l}\text { General natural } \\
\text { status }\end{array}$ & $\begin{array}{l}\text { Geographical } \\
\text { construction } \\
\text { components }\end{array}$ & $\begin{array}{l}\text { Natural } \\
\text { construction }\end{array}$ & $\begin{array}{l}\text { regional and natural } \\
\text { structural components }\end{array}$ & $\begin{array}{l}\text { Spot } \\
\text { components }\end{array}$ & $\begin{array}{l}\text { spot-linear } \\
\text { components }\end{array}$ \\
\hline $\begin{array}{r}\text { 1) the dominancy of } \\
\text { the ridge of Alborz } \\
\text { mountains (located } \\
\text { in the north, } \\
\text { possessing } \\
\text { numerous summits, } \\
\text { and having the } \\
\text { altitude of } 2800- \\
3200 \text { meters) over } \\
\text { city }\end{array}$ & $\begin{array}{l}\text { 1) the general slope } \\
\text { of the land is from } \\
\text { north to south with } \\
\text { low curvature } \\
\text { towards south-west } \\
\text { 2) The density of } \\
\text { floodway web } \\
\text { 3) heterogeneous } \\
\text { and uneven form of } \\
\text { the land }\end{array}$ & $\begin{array}{l}\text { 1) In west part of } \\
\text { the natural region } \\
\text { of New Hashtegrd } \\
\text { City, the Kordan } \\
\text { river's valley is } \\
\text { located and in east } \\
\text { part, the } \\
\text { Shalamzar (also } \\
\text { called hiv) river's } \\
\text { valley is placed } \\
\text { 2) the Fashand } \\
\text { river and the } \\
\text { Ardheh floodway } \\
\text { accompanied by } \\
\text { two other rivers, } \\
\text { namely Kordan } \\
\text { and Hive, play an } \\
\text { influential role on } \\
\text { the formation of } \\
\text { the unevenness of } \\
\text { the foothills. } \\
\text { 4) Relatively close } \\
\text { distances of the } \\
\text { rivers }\end{array}$ & $\begin{array}{l}\text { 4) rocky lands and steep } \\
\text { bare slopes without any soil } \\
\text { or proper plant covers in the } \\
\text { mountainous parts of the } \\
\text { area } \\
\text { 5) the meadows of the area } \\
\text { are mostly from camels } \\
\text { thorn type and located on } \\
\text { the slopes } \\
\text { 6) thorny types of plants, } \\
\text { which are Alborz types, are } \\
\text { more abundant and have } \\
\text { greater density in the foot of } \\
\text { the mountain }\end{array}$ & $\begin{array}{l}\text { 2) } 26 \text { springs } \\
\text { which are } \\
\text { considered to be } \\
\text { the most } \\
\text { important cause of } \\
\text { the discharge of } \\
\text { the groundwater } \\
\text { in this area } \\
\text { 3) } 46 \text { aqueduct } \\
\text { ranges providing } \\
\text { water with the } \\
\text { mean of } 18.4 \text { lit/s, } \\
\text { in other words, } \\
\text { they annually use } \\
26.65 \text { million m² } \\
\text { water of the } \\
\text { groundwater of } \\
\text { this plain. }\end{array}$ & $\begin{array}{l}\text { 2)The Fashand } \\
\text { River located } \\
\text { on the north } \\
\text { side of New } \\
\text { Hashtgerd City } \\
\text { and is emanated } \\
\text { from the south } \\
\text { slopes of } \\
\text { Zojkhani } \\
\text { Mountain with } \\
\text { the altitude of } \\
3200 \text { metres. }\end{array}$ \\
\hline
\end{tabular}

Source: (Behzadfar and Barin, 2009)

\section{RESULTS}

In order to gauge the extent of Hashtgerd New Town's inhabitants' consent in the statements designed in the questionnaire, number 3 was considered to be the criterion for the comparison of the participants' responds. Due to the fact that the questionnaire was designed according to the Likert Scale, number 3 was the average number. Table 4 represents the naturalism dimension status in Hashtgerd New Town. 
Table-2. The mean and Standard Deviation of the dimensions of naturalism index $(\mathrm{n}=379)$

\begin{tabular}{|c|c|c|}
\hline Factors & $\begin{array}{l}\text { Standard } \\
\text { Deviation }\end{array}$ & * Mean \\
\hline The rooms of your house are in a way that they let enough light in & 1.06 & 3.69 \\
\hline $\begin{array}{l}\text { For ventilation and tranquility of the interior space of the house, you mostly use the } \\
\text { natural air conditioning. }\end{array}$ & 1.16 & 3.39 \\
\hline Based on your own needs and interests, you grow plants in your house. & 1.17 & 2.45 \\
\hline In your neighborhood, there is a park or green open space available. & 1.23 & 2.68 \\
\hline There are enough parks and green open spaces available in your neighborhood and city. & 1.15 & 2.19 \\
\hline In public places of the city, spouts or fountains are placed. & 0.78 & 1.77 \\
\hline You can see natural views from your house & 1.13 & 2.76 \\
\hline From different places of the city you can see the natural views. & 0.98 & 2.69 \\
\hline Buildings and city passages hinder you from seeing the natural views. & $1 / 19$ & 2.76 \\
\hline The city contains an integrated sewerage. & 0.78 & 3.81 \\
\hline $\begin{array}{l}\text { Groundwater and surface water resources are protected from the environmental } \\
\text { pollutions. }\end{array}$ & 1.79 & 3.08 \\
\hline The sewage disposal system and garbage collection are not much efficient. & 0.87 & 3.28 \\
\hline Comings and goings of heavy trucks and cars bother you. & 1.11 & 3.57 \\
\hline Each house should have a pool or a small spout. & 1.40 & 3.09 \\
\hline Having a yard in the residential unit is necessary. & 1.28 & 2.17 \\
\hline Having a little garden in the yard of the residential unit is necessary. & 1.006 & 1.89 \\
\hline
\end{tabular}

\footnotetext{
*Based on the typical five-level items of Likert Scale: 1- Strongly disagree 2- Disagree 3- Neither agree nor disagree 4- Agree 5-Strongly agree
}

Table 2 reports the mean and SD of the investigated dimensions of naturalism for each statement of the designed questionnaire which is based on Lickert Scale. If the SD estimations are much less than their corresponding means, the participants' responds are very close; while in the cases where the SD estimations are bigger than their corresponding means, their answers are by no means close. The comparison between the standard mean of the statements in the index of naturalism with the obtained mean of the existing circumstances according to the participates' outlook demonstrates that the number obtained for the existing circumstances (i.e., 1.75) is less than the standard mean of the statements (i.e., 3). On the other hand, for the purpose of calculating the general status of the index, the whole mean of all the statements was gauged; and then regarding 3 as the standard mean and via recoding, three levels have been specified as follows: lower than the mean, the mean, above the mean. As the results illustrated, in the index of 
naturalism, $58 \%$ of the inhabitants' attitudes are less than the standard mean (Table 5). Therefore, it can be inferred that in the design of Hashtgerd New Town, the naturalism index has not received as much attention as it deserves by its constructors.

Table-3. The appraisal of Hashtgerd New Town based on the index of naturalism from participants' viewpoints

\begin{tabular}{ll}
\hline Levels & Naturalism \\
\hline Lower than mean & 58 \\
Mean & 10.6 \\
Above the mean & 31.4 \\
\hline
\end{tabular}

Source: Based on the field research and the author's calculation

So as to compute the realization of the index of naturalism in Hashtgerd New Town, a Onesample T-test was conducted. In the designed questionnaire, since the items didn't have the same directional coding, the recoding strategy was utilized to homogenize all the items in a way that all the negative items were recoded as positive ones. On the other hand, due to the fact that the fivelevel items of Likert Scale were adopted in the questionnaire, for the purpose of data analysis, five values are correspondingly considered (5- Strongly agreed, 4-agreed, 3- Neither agree nor disagree, 2-disagree, and 1- Strongly disagree). In order to run the One-sample T-test, number 3, as the standard mean, was multiplied by the number of statements in each dimension. The obtained result is the mean used to compare the naturalism index status. The results of the T-test demonstrate the mean of 46.88, 1.12 lower than the standard mean, for naturalism index. As the significant level is less than 0.05 , it can be declared that the difference between the obtained mean of the cases under examination and the standard mean is statistically significant. Considering the obtained mean of the existing circumstances in this city and its statistically significant difference with the standard mean, it can be inferred that regardless of all the emphasis Islamic religion lays on naturalism issues and heedless of ample attention the urban constructors have paid to the design of historic Iranian cities, unfortunately this index has been considerably overlooked in the design of Hashtgerd New Town.

Table-4. The status of naturalism index in Hashtgerd New Town

\begin{tabular}{llll}
\hline Mean of $\mathbf{4 8}$ & & & \\
\hline Index & mean of the existing status & Difference between means & Significant level \\
Naturalism & 46.88 & 1.12 & 0.001 \\
\hline
\end{tabular}

Source: Based on the field research and the authors' estimation 


\section{CONCLUSION AND SUGGESTIONS}

The achieved results on the theoretical basis suggest that the concept of Nature has received a great deal of reverence and attention in most cultures and all religions. In Ancient Iranian culture, Nature is composed mainly of four elements (Water, Soil, Wind, and Light). In Islamic culture, these elements and other natural phenomena are construed as the signs of the existence of God and are valuable reminiscences and reminders of this fact; therefore, in Islamic culture, the study of Nature and the discovery of laws reigned over it not only play a very outstanding role on the human guidance on knowing God better, but also are considered to be resourceful guides, assistants, and models for constructing a fitting environment which is in coordination with the order in the universe. Owing to the fact that the order in the universe and its characteristics, which are created by the one God, are perfect and flawless, the only way to construct a coordinated, balanced, and suitable artificial environment for human is to stay attuned with the order in the universe and to attempt to apply its characteristics in the construction of that artificial environment. The standpoint of the Iranian and Islamic culture regarding Nature is in consistent with Nature. This study was set forth to appraise naturalism index, as one of the most essential indices in Iranian Islamic urban construction, in Hashtgerd New Town. Bearing in mind this purpose, a questionnaire was designed and distributed among 379 inhabitants of Hashtgerd New Town. The comparison between the standard mean of the statements in the naturalism index and the obtained mean of the existing circumstances based on the participants' viewpoints indicated that the existing status (i.e., 1.75) is less than the standard mean (i.e., 3 ) and $58 \%$ of the inhabitants' responds were less than the standard mean. In order to figure out the extent of the realization of the naturalism index in Hashtgerd New Town, a One-sample t-test was run; the results reported the mean of 46.88 for the naturalism index, which is 1.12 less than the standard mean (i.e., 48). The findings of the field research, and of the study of maps, pictures, and the statistics pertaining to the existing green spaces in this new city provided evidence that the existing green spaces in the city is not sufficient for its inhabitants and the green spaces in the city do not cover the whole city regarding the radius function. Parks and the green spaces have not been dispersed in a balanced way; while parks, garden, and green spaces were present in 1, 2, and 4 districts, other areas seemed destitute of parks, gardens, and green spaces. No water could be seen in the fountains in the gardens and public places. Therefore, based on the findings of this study, the void of enough attention to the naturalism index in the construction of Hashtgerd New Town was confirmed. Even though it was expected that in the design of new cities sited on the natural pristine lands, the naturalism index, as one of the critical indices of the Iranian Islamic urban construction, should be methodically taken into consideration, this index was largely disregarded. Some informative suggestions, which may shed the light on this problem and pave the way for the improvement of the urban construction in consistence with naturalism index, are: 1) placing orchard spaces in either side of the city entrance, 2 ) enriching green spaces and plant covers in districts and neighborhoods, 3) being careful not to obstruct the surrounding natural views from the city passages, 4) avoiding causing damage to the surrounding natural environment in the process of urban development, 5) distributing green spaces in the city in a 
balanced proper way, 6) setting aside the natural pristine spaces around the city for public recreational use in their leisure time, 7) furnishing parks, gardens, and green spaces in the city with suitable pieces of equipment to be used more effectively by the city inhabitants, 8) building the residential blocks in districts considering the prevailing wind and Topography characteristics, 9) using the land's general slope for conducting and discharging surface waters, 10) upgrading the readability of the city via constructing green corridors towards the northern mountains of the city and the surrounding pristine areas. These suggestions can assist the designers of Hashtgerd New Town in implementing the naturalism index in this city.

\section{Funding: This study received no specific financial support.}

Competing Interests: The authors declare that they have no competing interests.

Contributors/Acknowledgement: All authors contributed equally to the conception and design of the study.

\section{RESOURCES}

Behzadfar, M. and A. Barin, 2009. Hashtgerd new town identification development. Urban structure Publication.

Esprin, A., 2006. The language of landscape, translation. Tehran University Publication. Kajy, H., 2000. Our identity. Tehran: ROZANEH Publication.

Nasr, H., 2000. The attitude of islamic world and the western modern science. Tehran: Soroush Publication, Noumber5.

Nasr, H., 2001. Human and nature, translation Tehran: Islamic Culture Office Publication.

Noghrehkar, A., 2009. An introduction to islamic identity in architectural and urban construction. Tehran: Research Center of Architectural and Urban Construction in Science and Technology University.

Rahimiyoun, A., 2011. The urban identity determination exploiting natural elements (the case study of hamedan city). Urban Identity Publication.

Shakouei, H., 1986. The social geography of cities. Tehran: Academic Jihad Publications.

Soltany, K., 1998. The anthology of urban construction discussion and approaches (life environment). Tehran: The Press Center Studies and Urban Research.

Taghi Zadeh, M., 2001. Drawing inspiration from nature in creating islamic life environment.

Taghi Zadeh, M., 2005. The role of nature in the advancement of urban beauty. Payam Sabz Publication. 